\title{
EL ARTE SÍ TIENE SEXO
}

\author{
María del Mar Rodríguez Caldas \\ Universidade de Vigo, Dpto Pintura
}

\begin{abstract}
Resumen
Partiendo de teorizaciones de Bourdieu y Heinich y empleando estudios de casos, ponemos el acento en la importancia de los reconocimientos simbólicos para el desempeño del trabajo artístico. Exponemos porqué siendo de gran trascendencia los actos de crédito intercambiados entre artistas, pueden presentar un marcado sesgo androcéntrico sin que por ello reciban una sanción negativa o, incluso, sean percibidos como tales. Con las recientes figuras del comisarix-autor y del artista-comisarix, junto con una creciente reflexividad hacia las convenciones expositivas, se ha abierto espacio para la participación de Ixs artistas en el tráfico de reconocimientos. Se observa ahí unas prácticas en las que el género femenino se revela un aspecto de minusvaloración, contraviniendo los logros feministas alcanzados en las instituciones artísticas. En relación a estas cuestiones, analizamos cómo la ratio de mujeres en la formación artística continúa en ascenso mientras sigue cediendo en el desarrollo profesional. La lógica de la dominación simbólica, la definición de la excelencia, las propiedades que definen al artista y la ideología carismática apuntalan un universo persistentemente sexuado.
\end{abstract}

\section{Palabras clave: GÉNERO EN EL ARTE; ARTISTAS; RECONOCIMIENTO ENTRE ARTISTAS; ARTISTA-CURADOR}

\section{ART DOES HAVE GENDER}

\begin{abstract}
In this paper, we will take Bourdieu and Heinich theories and we will use cases studies to emphasize the importance of symbolic recognition for the development of artistic work. We will expose why the acts of credit exchanged among artists have a great importance, they can show a marked androcentric bias without receiving a negative sanction or even being perceived. The curator-author and the artist-curator recent figures, together with a growing reflexivity towards the exhibition conventions, have renewed the participation of artists in the recognition traffic. In these practices, feminine gender often has an aspect of undervaluation, contravening feminist achievements in artistic institutions. In relation to these issues, we will analize the increase of women in artistic education and the assymmetry with their professional careers. The logic of symbolic domination, the definition of excellence, the qualities that define the figure of the artist and the charismatic ideology underpin a persistently sexuaded universe.
\end{abstract}

keywords: GENDER IN ART; ARTISTs; RECOGNITION AMONG ARTISTS; ARTIST-CURATOR

\footnotetext{
Rodríguez Caldas, María del Mar. 2019. "El arte sí tiene sexo". AusArt 7

(2): 61-76. DOI: 10.1387/ausart.21145
}

\section{AUSART}




\section{LA POBLACIÓN DE ARTISTAS. DEL RÉGIMEN AUTORITARIO AL COMPETITIVO}

Con la fundación de las academias oficiales de arte hacia finales del siglo XVII y principios del XVIII, se configura en Europa una institución diferenciada de los gremios del Medievo que tendrá potestad para definir qué es arte y para determinar quién tiene derecho a ser llamado artista. La práctica artística queda regulada por preceptos, convenciones y jerarquías; y la población de artistas presenta nítidos límites: la pertenencia a la Academia diferencia al artista del artesano, a los artistas 'auténticos' -con mayor capital cultural y económico- de los 'no auténticos'.

Ya en la Europa del siglo XIX, la Academia se convierte en un cuerpo de artistas de élite que se auto-reproduce: sus miembros eligen, con carácter vitalicio, a los jóvenes que se incorporan. La entrada en esta institución, además de acceso a la formación, proporcionaba reconocimiento social y artístico, ya que el cuerpo académico asesoraba a los poderes en materia de arte, escogía a quienes exponían en los salones, otorgaba los premios... ostentaba, en fin, el monopolio de la consagración artística.

La admisión de mujeres en ese hermético espacio era mínima y las que entraron "no gozaron nunca de los mismos privilegios que sus colegas varones: aunque en algunos casos se les autorizaba a participar en las reuniones, en ninguna de las academias europeas se les permitió asistir a las sesiones de dibujo del desnudo, dar clase o competir por la consecución de premios" (Mayayo 2010b, 34). Las artistas presionaron para derogar esas barreras y conquistaron la Academia hacia finales del siglo XIX, justamente cuando esta institución perdía su autoridad.

En efecto, como ha estudiado Bourdieu (1998), la revolución moderna relega a esa institución y se constituye el campo del arte autónomo, esto es, no controlado por un autoridad legitimante externa y en el cual se instaura la anomia. Ya no habrá una única definición legítima del arte y del artista, sino una pluralidad de posicionamientos en competencia, luchando por obtener la consagración artística que, ahora, sólo se determina dentro del campo.

Además, las fronteras de este campo son porosas y flexibles. A diferencia de otros, cuyo derecho de entrada está fuertemente codificado (por la posesión de una titulación, ganar una oposición, etc.), en el campo del arte la codifica- 
ción es débil (Bourdieu [1997] 2001, 335). Esto propicia importantes cambios morfológicos: la composición de la población de artistas deja de ser restringida y elitista, se diversifica y aumenta en volumen.

¿Cómo se desenvuelven las mujeres artistas en este nuevo microuniverso que, por un lado, se presenta como un espacio para la libertad artística, abierto a múltiples posibilidades; pero, por otro, es un lugar regido por interacciones agonísticas, en el que las invenciones ganan el reconocimiento de los otros partícipes del campo a base de confrontaciones y apoyos?

\section{FEMINIZACIÓN EN LA FORMACIÓN VERSUS MASCULINIZACIÓN EN LA PROFESIÓN}

Que el campo del arte resulta atractivo para las mujeres lo demuestran las cifras relativas a la formación. MAV ha informado del progresivo incremento de alumnas en los centros de bellas artes del estado español: en los años 50 un $30 \%$, en los 60 un $49 \%$, en los 80 un $54 \%$, en los 90 un $64 \%$, alcanzando en el periodo $2006 / 2010$ un $65 \%$. En otros países europeos la tasa referida a 2005/2013 igualmente supera el 60\% (MAV 2014).

Esta feminización de la formación contrasta con la masculinización de la práctica profesional plasmada en un estudio que, partiendo de los datos de la Visual Entidad de Gestión de Artistas Plásticos (VEGAP), estimaba la población de artistas españoles a fecha de 2003 en un $31,3 \%$ de mujeres y un $68,7 \%$ de hombres (AAVC 2006, 46) 1 .

Como vemos, estos datos del desempeño profesional de mujeres y hombres prácticamente invierten a los registrados en la formación artística ¿nos indican una baja tendencia entre las tituladas por seguir la profesión artística y, a la inversa, una alta orientación entre los titulados hacia dicha profesión?

\section{1. ¿Qué Sucede CON EL CAPITAL ARTístico dE LAS tituladas EN BELLAS ARTES?}

Sin embargo, de un estudio más reciente (Pérez y López-Aparicio 2018) se infería paridad en la población de artistas. Sus autores, calculando que el 
censo total ascendía a 25.000, lanzaron una encuesta en la que lograron la participación de 1.105 artistas, representando las mujeres un $52 \%$ y los hombres un $48 \%$. Un dato que, al contrario del anterior, indicaría que la orientación de las estudiantes hacia otras actividades profesionales no es elevada.

La divergencia de cifras entre ambos estudios parece deberse a las fuentes y metodología empleadas. El primer estudio, para extraer los datos relativos al género de Ixs artistas, recurrió a una entidad que gestiona los derechos de autor, lo cual implica obviar un considerable número de artistas no asociadxs a VEGAP. El propio estudio estimaba el censo total en 11.236, menos de la mitad que en el segundo estudio, y se elaboró bajo la premisa de excluir del análisis a "aquéllos que presentan una situación de menor visibilidad, ya sea por una dedicación de entretenimiento, más cercano al amateurismo que a la profesionalización, ya sea porque su carrera se está iniciado y todavía no ha tenido tiempo de entrar en los diversos circuitos existentes" (AAVC 2006, 45). Una categoría de artistas que, consideraban, sobrepasaba el $73 \%$ del censo total.

El segundo estudio, sin embargo, buscaba "llegar al mayor espectro posible de artistas" (Pérez \& López-Aparicio 2018, 48) y para ello se combinó el método casual -partiendo de la muestra constituida por artistas asociadxs en las distintas plataformas profesionales- con el muestreo de bola de nieve -expandiendo el número de artistas participantes en la encuesta a través de las redes sociales. Los resultados del estudio daban cabida a perfiles muy diversos, abarcando desde la elevada profesionalización hasta el ejercicio de la actividad sin contraprestación. Casi la mitad de Ixs encuestadxs declaraba recibir ingresos por debajo de $8.000 €$ al año -esto es, en el umbral del salario mínimo interprofesional (73-4) - y cerca del 30\% declaraba no recibir ingreso alguno por su actividad artística (89).

Considerando estos aspectos, quizá no es tanto que las tituladas en bellas artes inviertan su capital artístico fuera del campo del arte, sino que circula dentro de éste como un capital que es devaluado por causa de género. En otras palabras, parece plausible que entre Ixs artistas excluidxs del primer estudio por su baja visibilidad exista una población femenina que sí aflora en estudios en los que, como en el segundo, acogen una alta variedad de tipologías de artistas.

Aunque en este último estudio se echan en falta más indicadores desagregados por sexo para corroborar esta hipótesis, hay un dato muy significativo: de 
un $9,4 \%$ que consigue vivir de la actividad artística al proporcionarles entre el $75 \%$ y el $100 \%$ de sus ingresos, el $63 \%$ son hombres y el $37 \%$ mujeres. Es decir, si consideramos un ejercicio de la profesión estable y solvente, volvemos a unas cifras inversas a las registradas en la formación. Si el trabajo artístico se caracteriza por la incertidumbre y la precarización, las artistas son más vulnerables a la precariedad².

¿Cuántas mujeres han intentado, sin demasiado éxito, profesionalizarse como artistas? ¿durante cuánto tiempo? ¿invirtiendo cuántos esfuerzos? ¿cuáles son sus ingresos? ¿cuántas no perciben contraprestación económica? ¿cuántas desempeñan un segundo trabajo ( $\mathrm{y}$ un tercero en la esfera doméstica)? ¿cuántas resisten en estas condiciones y cuántas terminan por convertir la actividad complementaria en única?

La lucha de las mujeres por salvar los obstáculos y sortear los desvíos de la profesión artística frecuentemente conlleva altos costes y privaciones. Y, mientras para las artistas tiende a ser difícil compatibilizar su carrera con la vida familiar, para los artistas esta última tiende a ser un punto de apoyo para desplegar la primera. En este sentido, Mayayo ha planteado que no basta con reclamar mayor participación de las mujeres en el campo del arte, sino que se ha de reflexionar críticamente sobre las condiciones subjetivas y materiales en las que se produce esta participación (Mayayo 2010a, 311-2).

Análisis locales y globales (De la Villa 2011, 35; Díez 2012; Heartney et al. 2013, 10-2; 232; Reilly 2015; MAV 2019) han coincidido en que para las mujeres artistas el camino se estrecha más donde se adquieren seguridades y garantías económicas. Su menor presencia se registra, por un lado, en las exposiciones individuales en grandes museos; hito que sólo se produce tras haber cosechado importantes éxitos y que marca un momento profesional en el que se están acumulando beneficios simbólicos y los beneficios económicos prometen volverse regulares y ascendentes. $Y$, por otro, en el mercado del arte; prueba de que se confía en el valor constantemente creciente del producto (y de quien lo produce). Así, siendo baja la tasa de artistas del sexo femenino que logran estar representadas por galerías de $a^{2} e^{3}$, es mayor que la de aquellas que son promocionadas en ferias, la cual, a su vez, es mayor que la de artistas mujeres cuya obra llega a entrar en las subastas. Como indica Mayayo (2010a, 301), "el problema no consiste en que la presencia de las mujeres en el colectivo artístico sea minoritaria, sino además en que el resultado de su trabajo tiene una proyección mucho menor que la de sus colegas varones. Dicho de otro modo, a las mujeres no sólo les resulta más difícil 
convertirse en artistas profesionales, sino que una vez que lo consiguen les cuesta mucho más que su obra trascienda y sea aceptada por el establishment artístico".

\section{PROPIEDADES Y PODERES DEL MAGO}

Si el campo del arte se vuelve permeable a nuevas categorías de individuos, no todas ocuparán posiciones igual de ventajosas. Las diferencias en capital simbólico no impiden la entrada al campo, pero son factores de la dominación simbólica que tercian en la conquista de las posiciones más excepcionales y más buscadas y que influyen en la representación que los demás agentes se hacen respecto a si el/la artista se toma el juego del arte en serio (Bourdieu [1997] 2001).

¿Los agentes del campo del arte tienden a pensar que las artistas se lo toman en serio? ¿suelen tomarlas en serio en la misma medida que a sus colegas varones? ¿confían por un igual en el desarrollo de sus carreras?

Sobre la artista continúa pesando la sospecha de que abandonará o dejará en un segundo plano la producción artística al formar una familia (juego socialmente considerado de mayor seriedad para una mujer). Es frecuente que las artistas que han tenido descendencia redoblen su inversión en el juego del arte o hagan ver de forma muy explícita su apuesta por la profesión. O que otras que no la han tenido refrenden, en beneficio propio, el tópico de que la maternidad es incompatible con 'la entrega al arte'4.

La reflexión de Bourdieu sobre la relación entre la dominación social y la atribución de la excelencia es aplicable al campo del arte: "La definición de la excelencia está cargada, en cualquier ámbito, de implicaciones masculinas que tienen la particularidad de no aparecer como tales. La definición de un puesto, sobre todo investido de autoridad, incluye toda suerte de capacidades y de aptitudes sexualmente connotadas. (...) Para alcanzar plenamente cierta posición, una mujer tendría que poseer no sólo lo que exige explícitamente la descripción del puesto, sino también todo un conjunto de propiedades que sus ocupantes añaden habitualmente al mismo (disposiciones como agresividad, seguridad, la llamada autoridad natural... para las que los hombres han sido preparados en cuanto que hombres)" (Bourdieu [1998] 2013, 82). 
¿Cuáles son las propiedades que definen la figura del artista y que producen creencia en lo que hace? ¿Cuáles son los atributos del mago? Entre las características presupuestas a los 'grandes artistas' perduran valores asociados a la masculinidad e históricamente atribuidos al artista bohemio ${ }^{5}$. La rebeldía, el inconformismo y la audacia son propiedades productivas para hacer percibir las rupturas y expansiones en un campo gobernado por el continuo derribo de convenciones y nuevas anunciaciones. La insolencia, el desapego social, y hasta el malditismo, avalan una entrega en cuerpo y alma 'a la obra', a la vez que demuestran el desinterés por otros juegos sociales.

La reaparición intermitente de modelos de artista, así como la coincidencia en soslayar permanentemente a las mujeres desde posicionamientos artísticos profundamente divergentes, han sido referidas por Martha Rosler: así, el artista como héroe romántico reapareció en la posguerra incorporando rasgos autóctonos de la hombría y del trabajo productivo; por el contrario, el pop "rechazó el dominio masculino del expresionismo abstracto y jugó con el carácter femenino de la rendición" (Rosler [1983] 2011, 9) pero sin dejar espacio para la voz de una subjetividad femenina; el nuevo racionalismo (el land art, el minimal o el conceptual) reafirmó la cognición-masculina frente a lo intuitivo-femenino.

El dominio masculino ha sido fortalecido intensificándose el rol del macho (y obligando a las artistas a mostrarse 'superprofesionales', duras y 'masculinas' para ser aceptadas); pero también apropiándose de características consideradas femeninas. Battersby (1999) ha expuesto cómo la definición del artista romántico se modeló asimilando propiedades tradicionalmente femeninas -como la emocionalidad, la imaginación, la intuición o la espontaneidad- y reasignando a las mujeres valores inversos, tradicionalmente masculinos y ahora, en ellas, negativamente connotados -como la ponderación, la frialdad o la razón. Por su parte, Rosler ha identificado dos formas diferencialmente sexuadas de recuperar el mito romántico: mientras el artista expresionista lo hizo combatiendo la figura del artista americano afeminado, el neoexpresionista incorporaba los atributos de la subjetividad y la expresión que las artistas feministas habían hecho regresar: " $e l$ hombre de los ochenta' no teme mostrar su lado femenino, haciendo innecesario que las mujeres lo hagan" (Rosler [1983] 2011, 14).

Si, como hemos visto, la definición de la figura del artista está sujeta a constantes cambios -se reinventa invirtiendo y contrarrestando propiedadesmodelándose en diferentes momentos con atributos del lado de lo masculino o 
del lado de lo femenino y sin que por ello los habituales ocupantes pierdan sus puestos, la cuestión no es desvelar y desautorizar las propiedades que posee el mago en un momento dado, ni descubrir sus trucos, sino identificar el poder del cual el mago se apropia.

En el campo del arte impera "la ideología carismática que ensalza la figura del artista y lo entiende como un sujeto libre de todo condicionamiento, y que concibe implícitamente el 'genio' como un atributo masculino" (Méndez 2016, 83). Genio "denota una persona que destila experiencia y sensación activamente y cuyo talento reside en su habilidad para dominar y transformar ideas y sustancias - por medio de una facultad imaginativa innata- en una nueva entidad tangible que actúa poderosamente sobre la facultad estética receptiva del espectador". Esa figura casi divina excluye a las mujeres "en virtud de su terrenalidad y su cercanía a la Naturaleza, su compromiso con el nacimiento natural, (...), ya que, por supuesto, carne y espíritu no se mezclan" (Rosler [1983] 2011, 5).

La ideología carismática es la base de la creencia en el valor de la obra de arte. Si no se le reconoce el genio, la autoría y la autoridad al creador, no obra la eficacia mágica. Y si la persona del artista es central en la percepción y evaluación de las obras de arte contemporáneas (Heinich 2017,175), entonces podemos afirmar que el arte tiene sexo.

\section{EL TRÁFICO DE RECONOCIMIENTOS SIMBÓLICOS}

En un campo que supuestamente carece de orden y ley, entonces ¿rigen normas no escritas que discriminan por sexo (además de por otras características que actúan como coeficientes simbólicos negativos, como la etnia)? ¿Acaso para unos funciona como un campo en libre competencia por la legitimidad artística, mientras que para otras se asemeja al aparato jerarquizado y controlado por un cuerpo que antaño representaba la Academia?

En su estudio sobre la lógica y funcionamiento del campo del arte, Bourdieu (1998) lo define como un universo en el que quienes tienen la capacidad para reconocer la innovación son personas expertas. A mayor autonomía del campo, mayor peso tiene el juicio de los colegas de profesión, de aquellos que 
podrían haber hecho la misma invención que reconocen como tal. Si bien los artistas tienen gran poder de legitimación y ejercen control sobre las instancias de consagración, todo el conjunto de agentes e instituciones contribuye a producir el valor de la obra: críticos, historiadores del arte, editores, directores de galerías, marchantes, conservadores de museos, mecenas, coleccionistas, instancias políticas y administrativas, instituciones educativas, etc.

"Para dar una idea de la labor colectiva de la que es fruto [la consagración], habría que reconstituir la circulación de los innumerables actos de crédito que se intercambian entre todos los agentes comprometidos en el campo artístico, entre los artistas, evidentemente, con las exposiciones colectivas de grupo o los prefacios mediante los cuales los autores más consagrados consagran a los más jóvenes que a su vez los consagran como maestros o jefes de escuela, entre los artistas y los mecenas o los coleccionistas, entre los artistas y los críticos (...)" (Bourdieu [1997] 2001, 340-1).

Quedarse fuera de ese tráfico de aprobaciones y apoyos repercute no sólo en la falta de beneficios económicos y de recompensas simbólicas, afecta a la totalidad de la vida social y personal. Como observa Nathalie Heinich, el reconocimiento va más ligado al aprecio que al respeto y, en las actividades basadas en la vocación, "el reconocimiento tiene considerables efectos sobre la identidad personal, sobre la necesidad de restablecer la confianza en las propias capacidades, y sobre la confianza en uno mismo" $(2012,134)$. En este sentido, Louise Bourgeois ha expresado su sentimiento de no pertenencia al campo del arte o, mejor, de no tener derecho a esa pertenencia: "He sentido siempre un complejo de culpa a la hora de promocionar mi arte (...). Tenía la impresión de que la escena artística pertenecía a los hombres y de que de algún modo estaba invadiendo su terreno. Así, hacía el trabajo y luego lo escondía. Me sentía más cómoda escondiéndolo" (Bourgeois, citada en Mayayo 2010b,14).

Heinich ha explicado el proceso de reconocimiento adaptando la teoría de círculos concéntricos de Alan Bownes al arte contemporáneo (Heinich 2012 \& 2017). El primer círculo está formado por artistas, unos pocos pero cuyos juicios resultan decisivos, tanto más cuanto se trate de productos artísticos innovadores; el segundo está conformado por especialistas que trabajan en instituciones (críticos, comisarios, directores de museos...); el tercero por marchantes y coleccionistas; y el cuarto por el público amplio. 
Es un modelo que entrecruza tres dimensiones: la proximidad espacial, la temporalidad y el peso del reconocimiento. El reconocimiento entre los pares es de vital importancia; en primer lugar porque mientras los mediadores del $2^{\circ} \mathrm{y}$ $3^{\circ}$ círculo emiten su valoración a corto o medio plazo, y el público, en el $4^{\circ}$ y último círculo, lo hace a largo plazo, en el primero el juicio se recibe de forma inmediata y constituye un primer filtro que condiciona la recepción de la obra en los subsiguientes. En segundo lugar, porque el éxito en el proceso de reconocimiento depende de la competencia que se le reconoce a los jueces y ésta decrece del primero al cuarto círculo: "entre los distintos tipos de mediadores, un número reducido de los individuos, que no pagan con valores monetarios, sino con la fiabilidad de su criterio estético, son mucho más poderosos a la hora de influir en las evaluaciones de calidad que una multitud de admiradores" (Heinich 2012, 132).

\subsection{El reconocimiento entre artistas. Estudio de casos}

Entre estos trascendentes actos de crédito intercambiados por artistas, es interesante reparar en un nuevo modelo expositivo que revisa una trayectoria individual en relación dialógica con obras de otrxs autorxs. Un acto con el que el artista puede autoinscribirse en la historia del arte -rindiendo tributo a sus referentes- ponerse a la 'misma altura' que prestigiosos artistas coetáneos -designando a sus pares-y anunciar su 'futura grandeza' -nombrando a sus seguidores.

Señalaré dos casos que contrastan entre sí. En la exposición Jeff Wall. El sendero sinuoso, celebrada en 2011 en Bozar (Bruselas) y CGAC (Santiago de Compostela) ${ }^{6}$ dialogaban obras del fotógrafo canadiense con las de un elenco de artistas seleccionadas de forma conjunta por el propio Wall y por el comisario de la muestra, Jöel Benzakin (CGAC 2011). De 65 creadorxs (principalmente de las artes plásticas, bastantes de la fotografía, en menor medida del cine y algún autor literario) sólo dos $(3,1 \%)$ eran mujeres: Helen Lewitt y Diane Arbus. Ninguna de ellas era coetánea a Wall, de tal modo que no eran sus pares ni sus competidoras en el presente del campo del arte. Además ambas habían practicado la fotografía documental cuando esta disciplina y este género no tenían lugar en el campo del arte.

El régimen de "excepcionalidad" de la valía femenina que transmitía ese caso, contrasta con la cuasiparidad que se observa en la exposición Miquel Mont. Afinitats electives, celebrada en 2008 en La Panera y en 2009 en CRAC Languedoc-Roussillon: 'Un proyecto de Miquel Mont con la complicidad de Glòria Picazo y Nöelle Tissier' (Centre d'art La Panera 200877) directoras de los res- 
pectivos centros de arte. También a diferencia de la muestra de Wall, aquí el tipo de práctica que aunaba a Ixs artistas era muy compacta y pertenecían prácticamente a la misma generación.

Dos casos muy dispares y, también, con muy desigual repercusión en el campo globalizado del arte. Basta con considerar la "internacionalidad" de ambos artistas y del elenco que los acompaña, la de los agentes mediadores que los respaldan o la de las instituciones que los presentan al público para valorar la trascendencia de cada uno de estos dos actos de crédito. En otras palabras, sí importa la identidad de quienes otorgan el reconocimiento, ya que "la calidad de éste depende de la calidad de quienes lo conceden" (Heinich 2012, 132).

\subsection{El artista cOMO cOMisario. Estudio dE casos}

Otro acto de crédito entre artistas se produce cuando éstos intervienen en el comisariado de exposiciones colectivas. Desde la modernidad es práctica habitual que los artistas organicen exposiciones con sus afines, pero este formato ha adquirido una nueva dimensión con la definición de la figura del comisario y la delimitación de sus funciones, con el aumento de protagonismo de este agente en las últimas décadas y con el surgimiento de las variantes del comisarix-autor y el comisarix-performativo (Farquharson 2003; O'Neill 2016).

\begin{tabular}{|c|c|c|c|}
\hline EXPOSICIONES & ARTISTAS H & ARTISTAS M & Obra col. \\
\hline $\begin{array}{l}\text { Moral Maze. Le Consortium, Dijon. } 1995 \\
\text { Comisariado Liam Gillick y Philippe Parreno }\end{array}$ & $\begin{array}{c}10 \\
(83,3 \%)\end{array}$ & $\begin{array}{c}2 \\
(16,7 \%)\end{array}$ & - \\
\hline $\begin{array}{l}\text { All Hawaii Entrees/Lunar Reggae. IMMA, } \\
\text { Dublín. } 2006 \\
\text { Comisariado *Rachael Thomas y Philippe } \\
\text { Parreno }\end{array}$ & $\begin{array}{c}15 \\
(71,4 \%)\end{array}$ & $\begin{array}{c}6 \\
(28,6 \%)\end{array}$ & - \\
\hline $\begin{array}{l}\text { Moment Ginza. Magasin, Grenoble / } \\
\text { Färgfabriken, Estocolmo. 1997. Comisariado } \\
\text { Dominique Gonzalez-Foerster }\end{array}$ & $\begin{array}{c}7 \\
(70 \%)\end{array}$ & $\begin{array}{c}3 \\
(30 \%)\end{array}$ & $\begin{array}{l}3 \\
-\end{array}$ \\
\hline $\begin{array}{l}\text { Il Tempo del Postino. Manchester Opera House. } \\
2007 \\
\text { Comisariado *Hans Ulrich Obrist y Philippe } \\
\text { Parreno }\end{array}$ & $\begin{array}{c}9 \\
(69,2 \%)\end{array}$ & $\begin{array}{c}4 \\
(30,8 \%)\end{array}$ & $\begin{array}{l}1 \\
-\end{array}$ \\
\hline $\begin{array}{l}\text { What if. Art on the verge of Architecture and } \\
\text { Design. } \\
\text { Moderna Museet, Stockholm. } 2000 \\
\text { Comisariado *Maria Lind, colaboración Liam } \\
\quad \text { Gillick }\end{array}$ & $\begin{array}{c}13 \\
(50 \%)\end{array}$ & $\begin{array}{c}13 \\
(50 \%)\end{array}$ & $\begin{array}{l}3 \\
-\end{array}$ \\
\hline
\end{tabular}

Figura 1. Exposiciones de "arte relacional" con participación de artistas en el comisariado

Fuente: Elaboración propia a partir de datos recogidos en Guasch (2009) y páginas web de las institucio- 
Ha sido frecuente el paradigma del 'artista como comisarix' en las exposiciones del arte relacional ${ }^{9}$ por ser prácticas que revisan las convenciones y los planteamientos expositivos. A la vista de los datos recopilados en la Figura 1 , sorprende que artistas nacidxs en la década de los 60 , que se formaron cuando las mujeres ya eran amplia mayoría en las aulas, las reconozcan tan poco. E inquieta que el peor dato del listado se registre en la única muestra comisariada exclusivamente por artistas varones: Moral Maze. Por contra, hallamos una exacta paridad en la exposición en la cual el artista Liam Gillick colabora con una mediadora del $2^{\circ}$ círculo. Si bien es cierto que Maria Lind fue propiamente la comisaria, mientras Gillick participó en el proceso de consulta y posteriormente se encargó del montaje y diseño de la exposición, como también es cierto que la entonces curadora del Moderna Museet se formó en teoría feminista.

Otro ejemplo, reflejado en la Figura 2, lo hallamos en el colectivo de artistas formado por Michael Elmgreen e Ingar Dragset que, problematizando la exposición como medio, han recalado con éxito en el comisariado. Nacidos también en los 60 , desconcierta que apenas den cabida a un $18 \%$ de artistas mujeres en The Others (2016) y que hayan recibido la Mención Especial de la Bienal de Venecia por The Collectors (2009), de elevado sesgo androcéntrico. De nuevo vuelve a producirse, dentro de lo que cabe, mejor ratio cuando los artistas trabajan con una mediadora del $2^{\circ}$ círculo (la entonces directora artística de Künstlerhaus Bremen, Susanne Pfeffer) y prácticamente se alcanza la paridad cuando en la Bienal de Estambul cuentan con un equipo asesor de 5 personas, de las cuales 4 son mujeres.

\begin{tabular}{|c|c|c|c|}
\hline EXPOSICIONES & ARTISTAS H & ARTISTAS M & Obra col. \\
\hline The Others. Köning Galerie, Berlín. 2016 & $\begin{array}{c}9 \\
(81,8 \%)\end{array}$ & $\begin{array}{c}2 \\
(18,2 \%)\end{array}$ & $\begin{array}{l}1 \\
-\end{array}$ \\
\hline The Collectors. 53 Bienal de Venecia. 2009 & $\begin{array}{c}15 \\
(71,4 \%)\end{array}$ & $\begin{array}{c}6 \\
(28,6 \%)\end{array}$ & $\begin{array}{l}3 \\
-\end{array}$ \\
\hline A Space Called Public. Munich. 2013 & $\begin{array}{c}8 \\
(66,7 \%)\end{array}$ & $\begin{array}{c}4 \\
(33,3 \%)\end{array}$ & $\begin{array}{l}5 \\
-\end{array}$ \\
\hline $\begin{array}{l}\text { Not a Drop but the Fall. Künstlerhaus } \\
\text { Bremen. } 2005 \\
\text { Co-comisariada con *Susanne Pfeffer }\end{array}$ & $\begin{array}{c}11 \\
(64,7 \%)\end{array}$ & $\begin{array}{c}6 \\
(35,3 \%)\end{array}$ & $\begin{array}{l}1 \\
-\end{array}$ \\
\hline $\begin{array}{l}\text { Bienal de Estambul, } 2017 \\
\text { Equipo asesor*: Adriano Pedrosa, Basak } \\
\text { Senova, Inci Eviner, Iwona Blazwich y Ute } \\
\text { Meta Bauer }\end{array}$ & $\begin{array}{c}29 \\
(55,8 \%)\end{array}$ & $\begin{array}{c}23 \\
(44,2 \%)\end{array}$ & $\begin{array}{l}3 \\
-\end{array}$ \\
\hline
\end{tabular}

Figura 2. Exposiciones comisariadas por Elmgreen \& Dragset

Fuente: Elaboración propia a partir de los datos recogidos en las páginas web de las instituciones. 
Frente al compromiso y responsabilidad que Ixs profesionales del comisariado adquieren con su propio trabajo y con la institución para la que trabajan, Ixs artistas pueden permitirse ciertas licencias y, en nombre de la 'creatividad', ahora aplicada al formato expositivo, quedan eximidos de justificar las selecciones (sexistas) que realizan. ¿Acaso esta 'libertad de elección' no facilita que campe a sus anchas la visión androcéntrica sin recibir ningún tipo de sanción?

Otra fórmula de intercambio de actos de crédito consiste en la invitación del artista-comisario a sus colegas-artistas para que desarrollen una obra a partir de unas premisas.

En la 50 Bienal de Venecia de 2003, en pleno corazón del 'mundo globalizado del arte', Gabriel Orozco comisarió una muestra $100 \%$ masculina en la que participaban 6 artistas colegas: The everyday altered.

En No Ghost Just a Shell -célebre proyecto de Philippe Parreno y Pierre Huyghe iniciado en 1999 que itineró por Kunsthalle Zürich, SF MOMA y Van Abbemuseum (2002/03) e integra las colecciones de ICA Miami, Van Abbemuseum y Tate Modern- han participado, además de 3 colectivos, 3 artistas mujeres (25\%) y 9 hombres $(75 \%)$.

También está presente en la colección de la Tate On year celebration (2006) propuesta en el que Pierre Huygue invita a varixs artistas visuales, algún escritor y al comisario Hans Ulrich Obrist. El carácter más modesto que el proyecto anterior no es óbice para que su desequilibrio sea mayor: 5 colectivos, 7 mujeres $(18,9 \%)$ y 30 hombres $(81,1 \%)$. Destacable, por 'tocarnos de cerca', es el proyecto del pontevedrés Misha Bies Golas, mostrado en Santiago de Compostela cuando el artista había reunido 27 monocromos de $20 \times 20 \mathrm{~cm}$. realizados por otrxs tantxs artistas (Misha Bies Golas. 27 Negros, 2013-2014, CGAC, 2014) y expuesto después en Valencia contando con mayor participación (50 negros, Sala Josep Renau, 2016). Proyecto con ambición menor y localismo mayor que los anteriores, pero con igual falta de originalidad en cuanto a la composición de artistas: 10 mujeres $(20 \%), 40$ hombres $(80 \%)^{10}$. A la vista de estos últimos casos, se diría que es esta un tipo de propuesta todavía menos propicia para las mujeres artistas. 


\section{CODA}

Aunque la recopilación de esta serie de casos no tiene pretensión de representatividad, sí se aportan desde la convicción de su repercusión en el campo del arte. Existen, están ahí, producen efectos.

Si localizáramos exposiciones comisariadas por artistas concienzadxs en la desigualdad entre los géneros, los resultados, afortunadamente, serían otros.

La cuestión es que mientras que las exposiciones que se enuncian como contribuciones a las políticas de igualdad o como acciones positivas ( $\mathrm{y}$ el hecho de que lo expliciten reivindicativamente, importa) proceden de una conciencia feminista y constituyen un apoyo decidido a las mujeres artistas, aquellas otras exposiciones que sin manifestarlo apoyan manifiestamente a los hombres artistas, constituyen 'mentorings' espontáneos (nada tienen de estrategias de resistencia organizadas, como sí lo son las anteriores) que se presentan como acciones 'neutras', sin necesidad alguna de enunciarse en un discurso que justifique el sesgo androcéntrico.

En la sociedad actual la dominación masculina ya no se impone como algo obvio: gracias a que el movimiento feminista ha roto el círculo del refuerzo generalizado, ahora ese dominio se tiene que defender o justificar. En el campo del arte, gracias a que el feminismo se ha ido abriendo paso desde los 60 , se va consiguiendo que las instituciones y sus agentes responsables tengan que dar explicaciones por sus políticas sexistas (expositivas, de compras, etc.) pero queda pendiente romper con el círculo de los reconocimientos entre artistas, agentes que se pueden permitir perpetuar el dominio masculino en nombre de la 'libertad creativa'.

No es tarea menor dada la incidencia de estos actos de crédito -como se ha explicado a partir de Bourdieu y Heinich- en los demás espacios y fases del proceso del reconocimiento artístico. Son múltiples 'pequeños' gestos que tienen la capacidad de producir 'grandes' resultados. Acompañan en cualquier momento de una trayectoria profesional: ya emergen en los inicios de la andadura artística y siguen produciéndose $-y$ siendo productivos- cuando se ha alcanzado renombre profesional. 


\section{Referencias bibliográficas}

AAVC (Associacio d'Artistes Visuals de Catalunya). 2006. La dimensión económica de las artes visuales en España. Barcelona: Associació d'Artistes Visuals de Catalunya

Alonso, Mónica. 2015. "Arte, feminismo y maternidad" M arte y cultura visual, 19 marzo. https:// www.m-arteyculturavisual.com/2015/03/19/arte-feminismo-y-maternidad/

Battersby, Christine. 1999. Gender and genius: Towards a feminist aesthetics. London: The Women's

Bourdieu, Pierre. (1997) 2001. Las reglas del arte: Génesis y estructura del campo literario. Traducción de Thomas Kauf. Barcelona: Anagrama

— . . (1998) 2013. La dominación masculina. Traducción de Joaquín Jordá. Barcelona: Anagrama

De la Villa Ardura, Rocío. 2011. "La disputa sexual por las imágenes: Las mujeres en el sistema del arte en el Estado español". En Mujeres y cultura: Políticas de igualdad, 33-40. Madrid: Ministerio de Cultura

Díez Huertas, Celia. 2012. "Las artistas españolas y el mercado del arte: Una reflexión sobre las causas de su desencuentro". En Mujeres en el sistema del arte en España, 174-80. Madrid: Mujeres en las Artes Visuales Exit

Farquharson, Alex. 2003. "Curator and artist". Art Monthly 270. http://www.artmonthly.co.uk/ magazine/site/article/curator-and-artist-by-alex-farquharson-october-2003

Guasch, Anna María. 2009. El arte del siglo XX en sus exposiciones 1945-2007. Barcelona: Serbal

Heartney, Eleanor, Helaine Posner, Nancy Princenthal \& Sue Scott. 2013. The reckoning: Women artists of the new millenium. Munich: Prestel

Heinich, Nathalie. 2012. "El reconocimiento en el arte". En Ekoizpen artistikoa eta artearen teoria feminista: Eztabaida berriak IV, 127-36. Vitoria-Gasteiz: Ayuntamiento de Vitoria-Gasteiz

- . 2017. El paradigma del arte contemporáneo: Estructuras de una revolución artística. Traducción de Agustín Temes y Étienne Barr. Madrid: Casimiro

Marzo Pérez, Jorge Luis. 2005. "Artistas: entre náufragos y promotores turísticos". En Jornadas "El estatus del artista", AVAM-Artistas Visuales Asociados de Madrid, Centro Cultural Conde Duque, 24 nov. https://www.soymenos.net/naufragos.pdf

MAV (Mujeres en las Artes Visuales). 2015. "Las mujeres y el sistema del arte visual en Europa". Informe MAV 13. www.m-arteyculturavisual.com/wp-content/uploads/2015/01/ Informe-13-Europa-OK.pdf

— . 2019. "Informes MAV Ferias 2019". https://mav.org.es/informes-mav-ferias-2019/

Mayayo Bost, Patricia. 2010a. "¿Hacia una normalización? El papel de las mujeres en el sistema del arte español". En El sistema del arte en España, Juan Antonio Ramírez, ed., 297-333. Madrid: Cátedra

— . 2010b. Historias de mujeres, historias del arte. Madrid: Cátedra

Méndez Pérez, Lourdes. 2016. "Entre avances y retrocesos: retos para una antropología feminista del campo del arte". Nierika 10: 76-92

O'Neill, Paul. 2016. The Culture of curating and the curating of culture(s). Cambridge MA: MIT 
Pérez Ibáñez, Marta \& López Aparicio, Isidro. 2018. La actividad económica de los/las artistas en España: Estudio y análisis. Granada: Universidad de Granada

Reilly, Maura. 2015. "Taking the measure of sexism: Facts, figures and fixes" Artnews, 26 May. http://www.artnews.com/2015/05/26/taking-the-measure-of-sexism-facts-figures-and-fixes/

Rosler, Marta. (1983) 2011. “La figura del artista, la figura de la mujer”. Traducción a cargo de Maite Aldaz y Aurelio Sainz Pezonaga. Youkali 11: 5-14

Ruido Pidre, María. 2004. "Mamá, ¡Quiero ser artista! Apuntes sobre la situación de algunas trabajadoras en el sector de la producción de imágenes, aquí y ahora". En A la deriva por los circuitos de la precariedad femenina, Precarias a la deriva, 259-67. Madrid: Traficantes de Sueños.

\section{Notas}

${ }^{1}$ El estudio fue elaborado por Artimetría y Urbemedia a petición de la Associació d'Artistes Visuals de Catalunya.

${ }^{2}$ Ver al respecto el texto de Maria Ruido Mamá, ¡Quiero ser artista! (Ruido 2004).

${ }^{3}$ Resulta paradójico que de un selecto grupo de 25 mujeres artistas con recorrido internacional recogido en un volumen de la prestigiosa editorial Prestel -artistas nacidas después de los $60 \mathrm{y}$, como indican las autoras, ya beneficiadas por el camino que han abierto sus predecesoras- varias carezcan de representación en galería (Heartney et al. 2013, 7 y 12).

${ }^{4}$ Sobre las declaraciones al respecto de Marina Abramovic y Tracey Emin, ver las reflexiones de Mónica Alonso (2015).

${ }^{5}$ Jorge Luis Marzo (2005) ha identificado la herencia del outsider bohemio en un modelo de artista actual que él denomina "el náufrago". Y ha evidenciando su pervivencia mítica a través de citas de responsables de la política cultural española: la autenticidad, la individualidad, la necesidad de silencio y soledad, son propiedades y disposiciones alabadas en sus discursos.

6 "Jeff Wall. The crooked path", Centro Galego de Arte Contemporánea (CGAC), 2011. https:// issuu.com/biblioteca-cgac/docs/folleto_exposicion_jeff_wall_

7 "Afinidades electivas", Centre d'Art La Panera Lleida, 2008 http://www.lapanera.cat/home. php?op=9\&module=programacio\&cad $=1 \&$ item $=42$

${ }^{8}$ En esta Figura y en la siguiente, se señalan con asterisco * a aquellos agentes que no son artistas y actúan como co-comisariados sea desde su pertenencia al equipo de la institución expositiva o sea como comisarios independientes.

${ }^{9}$ Las muestras aquí listadas son las que figuran en el capítulo "El arte relacional y la estética de laboratorio" del libro de Anna Maria Guasch (2009, 421-35).

${ }^{10}$ Recientemente localizamos idéntica dinámica en otro evento local: en octubre de 2019 se inauguraba la exposición "Un martillo, dos martillos" en Maison Ruina, un espacio alternativo de Vigo. Comisariada por un ex-alumno de BBAA de Pontevedra, se proponía informar de las prácticas pictóricas y escultóricas actuales a través de una selección de profesorxs y ex-alumnxs. De 15 artistas, 4 eran mujeres $(26,7 \%)$, cifra que dejaba claro la poca maestría reconocida a las profesoras y el poco interés concedido a las compañeras.

(Artículo recibido: 12-10-19; aceptado: 11-12-19) 